Pathophysiology Haemostasis and Thrombosis

\title{
Matrix Metalloproteases and Tumor Dissemination
}

\author{
James P. Quigley \\ Department of Cell Biology, Division of Vascular Biology, The Scripps Research Institute, La Jolla, Calif., USA
}

In order for primary tumors to disseminate to secondary organs, they must undergo a number of prerequisite processes and molecular events. These events and processes include growth and establishment of the primary tumor, angiogenesis and vascular infiltration of the primary tumor, invasion and entry of tumor cells into the vascular circulation (a process known as intravasation), survival of tumor cells in the circulation, arrest in the microcirculation of the secondary organ, exit from the vasculature in the secondary site (a process known as extravasation), and finally growth and establishment of metastatic foci. The relevant molecular events that occur within this metastatic cascade can accurately be studied only with in vivo animal model systems. Quantification of the in vivo model systems is often difficult.

Our laboratory has recently established quantitative in vivo assays for angiogenesis [1] and human tumor cell metastasis [2] employing the developing chick embryo as the host animal. These assays are more facile (allowing for molecular intervention) and more rapid (occurring over a 3-7 day time period) than the standard in vivo mouse assays which often require 2 weeks to 2 months duration.

One of the protein families that we have examined for their possible functional role in our angiogenesis and/or metastasis models are the matrix metalloproteinases

\begin{tabular}{|c|c|}
\hline KARGER & $\begin{array}{l}\text { (c) } 2003 \text { S. Karger AG, Basel } \\
1424-8832 / 03 / 0337-0062 \$ 19.50 / 0\end{array}$ \\
\hline $\begin{array}{l}\text { Fax +41613061234 } \\
\text { E-Mail karger@karger.ch } \\
\text { www.karger.com }\end{array}$ & $\begin{array}{l}\text { Accessible online at: } \\
\text { www.karger.com/journals/pht }\end{array}$ \\
\hline
\end{tabular}

(MMPs). These enzymes, secreted or membrane anchored, are produced by distinct cell types and have been shown to cleave a variety of extracellular matrix components and also to activate by select cleavage other MMPs, growth factors and cytokines.

In the angiogenesis model system we have shown that a sub-set of the MMPs, namely the interstitial collagenases, contribute a rate-limiting reaction to the vascular remodeling events that precede new blood vessel formation. We have been able to demonstrate the specific involvement of these collagenases by taking advantage of a genetically modified type I collagen $(\mathrm{r} / \mathrm{r}$ collagen). This collagen is mutated at a single locus such that it is resistant specifically to cleavage by interstitial collagenases but is equal to wild type in its susceptibility to the gelatinases. When this mutant collagen is used in vivo as the underlying substratum, the sprouting endothelial cells exhibit a dramatically reduced ability to form new blood vessels when compared to their ability to do so on wild type collagen. The distinct MMPs that contribute to the specific cleavage of collagen in the angiogenesis model system are being identified and characterized.

In the metastasis model system, specific MMP inhibitors have been shown to block some of the aforementioned steps in the metastatic cascade. One step that appears to be

Dr. James P. Quigley

Department of Cell Biology, Division of Vascular Biology

The Scripps Research Institute

10550 N Torrey Pines Rd/VB1, La Jolla, CA 92037 (USA)

Tel.+1 858784 7108, Fax +1858784 7333, E-Mail jquigley@scripps.edu 
functionally linked to the action of MMPs is the intravasation process. Other steps in the cascade that now can be quantified in our model system are being examined for sensitivity to specific MMP inhibitors. The identification of the relevant MMPs is being actively pursued.

\section{References} RT, Quigley JP: Growth factor-induced angiogenesis in vivo requires specific cleavage of fibrillar type I collagen. Blood 2001;97:2323

2 Zijlstra A, Mellor R, Panzarella G, Aimes RT, Marchenko N, Quigley JP: A quantitative analysis of the metastatic cascade of human tumor cells using human specific real-time PCR. Cancer Research 2002;62:7083-7092. 